\title{
Training the Next Generation of Teaching Professors: A Comparative Study of Ph.D. Programs in Political Science
}

John Ishiyama, University of North Texas

Tom Miles, University of North Texas

Christine Balarezo, University of North Texas

ABSTRACT In this article, we investigate the graduate curricula of political science programs and 122 Ph.D.-granting political science programs in the United States and how they seek to prepare political science teachers. We first investigate whether the department offers a dedicated political science course at the graduatelevel on college teaching, and whether the presence of this class correlates with the size of the department, the size of the university, the ranking of the department, and so on. We find that whether a program offers a graduate course on teaching is inversely related to the research productivity of a department, and that departments at public institutions are more likely to offer such courses than are departments at private institutions. Second, we conduct content analysis of a sample of syllabifrom departments that offer such courses to ascertain the kinds of topics that are covered. Finally, we briefly describe some model programs that seek to prepare graduate students for teaching careers that integrate graduate student teacher training throughout the Ph.D. program.

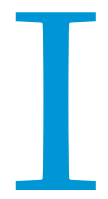

$\mathrm{n}$ this article, we investigate the graduate curriculum of political science programs across 122 Ph.D.-granting political science programs in the United States and examine whether the programs offer a graduate course on teaching political science. Little or no systematic work has been conducted that investigates the proportion of $\mathrm{Ph}$.D. programs that overtly prepare their graduates for teaching in the profession. In conducting such an examination, we first investigate whether the department offers a dedicated course at the graduate level on college teaching, and whether this offering correlates with the size of the department, the size of the university,

John Ishiyama is a professor of political science at the University of North Texas. He has published extensively on political parties, democratization, and ethnic politics in postCommunist East Central European and former Soviet Union politics and Africa, and the scholarship of teaching and learning. He can be reached at John.Ishiyama@unt.edu. Tom Miles is a Ph.D. student at the University of North Texas. His research focuses on environmental and science policymaking in the U.S. Congress. His recent work has appeared in the American Review of Politics. He can be reached at tdmoo79@unt.edu. Christine Balarezo is a Ph.D. student in political science at the University of North Texas. Her main research interests are contemporary global slavery, human rights, women and children, and the Andean region. She can be reached at oreocab@aol.com. and the ranking of the department, among other factors. Second, we conduct a content analysis of a sample of syllabi from departments that offer such courses to ascertain the kinds of topics that are covered. Finally, we briefly describe some model programs that seek to prepare graduate students for teaching careers that integrate graduate student teacher training throughout the Ph.D. program. This project purports to fill an important gap in our understanding of how our discipline as a whole trains future political science teachers.

\section{LITERATURE}

Over the years, there has been an increasing call to improve the quality of graduate education in the social sciences. In particular, many studies have indicated that in the social sciences, graduate programs have failed to adequately prepare doctoral students for the changing character of higher education, particularly in terms of teacher training for careers at institutions that emphasize undergraduate teaching. Indeed, there is considerable evidence that most available faculty positions are located at institutions that primarily focus on teaching. A study in 2003 indicated that about $72 \%$ of doctoral graduates in political science pursue academic careers 
(Nerad and Cerny 2003), as compared to $50 \%$ of doctoral graduates from all fields (Hoffer et al. 2002). However, only $26 \%$ to $35 \%$ of faculty positions in political science are located at doctoralgranting departments. ${ }^{1}$ Thus, only about one-third of doctoral graduates in political science can expect to become faculty members at research universities that are similar to their graduate institution, where research and publication are the predominant requirements for earning tenure. The remaining positions are located at other types of institutions, where teaching and professional and community service roles are of equal or greater importance than research and publication.

However, as Gaff et al. (2003) note in their study of doctoral programs in political science, most graduate programs do not adequately prepare graduate students for the realities of faculty life at the institutions where most will begin their careers. They contend that "better preparation for academic careers includes understanding the missions, faculty roles and rewards, and academic culture of the various institutions. Preparation should also allow students to experience the full range of roles faculty play in these institutions and to develop the skills that will allow them to compete for and succeed in faculty positions" $(2003,2)$. In particular, they point to a lack of adequate preparation for and four Ph.D.-granting institutions in political science-Indiana University, University of Colorado-Boulder, Howard University, and the University of Illinois-Chicago).

Some political science departments have already fashioned their programs to explicitly prepare students for careers as teacher scholars. The political science department of Miami University (Ohio), for example, established a College Professor Training Program for its doctoral students, which includes a mentoring program to train students for independent teaching and coursework on teaching political science to undergraduates. Similarly, Baylor University inaugurated a new Ph.D. program in political science in 2005 that has been designed specifically to train teacher scholars.

Despite calls for improving graduate student teacher training in the profession, no research has been conducted of which we are aware that systematically examines the extent to which Ph.D.granting programs in political science train graduate students for careers as political science teachers. To be sure, several recent works have examined graduate student experiences as "trainees" (see Hesli, Fink, and Duffy 2003; Buehler and Marcum 2007) and have offered recommendations to improve the content of graduate student training. Others have examined programs that have produced "award winning teachers" (Cole and Ishiyama 2008), but

\section{A recent APSA task force report on graduate education (2004) argued that with the growing number of employment opportunities for graduates of political science Ph.D. programs at primarily undergraduate institutions (PUIS) and community colleges, many departments must prepare students to be not simply political scientists, but also teachers of political science. This shift does not mean the abandonment of scholarship, but rather the creation of "teacher-scholars," or individuals who are trained to both conduct independent and innovative scholarly work and have the skills to effectively impart knowledge to undergraduate students.}

careers as teachers. Indeed, although many graduate students have an opportunity to teach sometime during their experience as doctoral students, their programs do not often provide structured experiences that prepare them to deal with issues such as "assessment, different types of student learning, the pedagogy of the discipline, curricular innovations, the impact of technology on education, or the variety of teaching styles that may be helpful with students from different racial, ethnic, or cultural backgrounds" (3).

A recent APSA task force report on graduate education (2004) argued that with the growing number of employment opportunities for graduates of political science Ph.D. programs at primarily undergraduate institutions (PUIs) and community colleges, many departments must prepare students to be not simply political scientists, but also teachers of political science. This shift does not mean the abandonment of scholarship, but rather the creation of "teacher-scholars," or individuals who are trained to both conduct independent and innovative scholarly work and have the skills to effectively impart knowledge to undergraduate students. Other efforts to improve teacher training and professional preparation for careers at PUIs have included the Preparing Future Faculty (PFF) programs (PFF 4 included the APSA nothing has been published that broadly reviews the extent to which Ph.D.-granting departments explicitly train graduate students on how to teach. In particular, there is little or no systematic work that investigates the proportion of Ph.D. programs that overtly prepare their graduates for teaching (by offering a dedicated graduate course that trains teachers) in the profession.

Given these assertions regarding the current emphasis on research and publication at most graduate programs, one hypothesis based on the current literature is that departments that emphasize research productivity would be less likely to offer a course on political science teaching, given their emphasis on placing their graduates in Ph.D.-granting departments. Indeed, even the current rankings of programs are based not on all placements, but on the placement of students at Ph.D.-granting departments (see, e.g., Masuoka, Grofman, and Feld 2007). Furthermore, programs that may not be high on the list of rankings may seek to prepare their graduates for placement in any job and, hence, may be more likely to arm their graduates with the tools to secure positions at colleges and universities that value teaching and community service more than research and publication. Thus, we might expect that larger departments (in terms of full-time equivalent [FTE] faculty) at larger institutions (in terms of number of students) 
with more highly ranked departments (in terms of research productivity) would be less likely to offer their graduate students formal training on teaching than smaller departments at smaller universities that are ranked lower in terms of research productivity.

\section{DATA}

How many political science Ph.D. programs offer teacher training courses for graduate students? For the macro-level, quantitative part of the analysis, we collected data on 129 political science Ph.D. programs in the United States, as identified by the APSA (http:// www.apsanet.org/content_6947.cfm). We coded any instance in which there was some indication of a formalized practice in a classroom setting of teacher training, such as a formal class, seminar, or guided practicum. These practices were taken as indications of a departmental commitment to teacher training, given that they require some investment of resources (e.g., salary, instructional time, classroom space, class room, seminar materials). We did not include less formal programs such as guided teaching (without a formal seminar/class component) that may require time commitment on the part of the director of graduate studies but do not require other significant classroom resources. Further, we coded whether the class or seminar was required of someone (e.g., all graduate students, only teaching assistants).

We coded each Ph.D.-granting department listed by the APSA. Of the $129 \mathrm{Ph} . \mathrm{D}$. programs listed, we omitted several programs that were primarily based on producing practitioners, as opposed to faculty. These included programs such as Harvard University's John F. Kennedy School of Government, the American University Graduate School for International Service; the Johns Hopkins University's Nitze School of Advanced International Studies, Princeton University's Woodrow Wilson School, Auburn University, and the University of Baltimore. Further, we could not discern data for at least one program. The removal of these programs reduced the total number of Ph.D.-granting departments to 122.

The data on whether the department offered a course on teaching political science at the graduate level were derived from an examination of the graduate catalogues of each department (if this document was unavailable, we relied on information culled from department Web sites). We also examined department and university Web sites to collect data on the number of FTE faculty members and the size of the institutions. Coding of the data from the 122 political science departments involved a team of four people (three graduate students at the University of North Texas and one faculty member). In this procedure, the graduate student researchers first coded the individual departments. The faculty member then reviewed the data and corrected any questionable codings after reviewing the graduate catalogues and Web sites. Of the 122 departments we investigated, 41 offered a graduate-level course on teaching political science. Of these 41 departments, 28 required that the course be taken by at least some of their graduate students. In 13 cases, the course was optional or listed as an elective.

Regarding the first independent variable, research productivity, we employed as a measure the international ranking of political science departments as reported by Simon Hix in 2004. The Hix ranking of political science programs assessed 1,255 programs (both U.S. and global programs) and ranked the 400 best institutions based on faculty productivity in the top 63 political science journals in the world, making it the most comprehensive ranking based on research productivity in existence. We used the
Table 1

Offering a Graduate Course on Teaching Political Science: Coefficient Estimates and Logit Analysis

\begin{tabular}{lc} 
VARIABLE & COEFFICIENT (exp b) \\
\hline Inverse of the Hix Index & $-.007^{*}(1.007)$ \\
\hline FTE Faculty in Department & $.032(1.030)$ \\
\hline $\begin{array}{l}\text { Total University Student Population } \\
\text { (in Categories) }\end{array}$ & $.126(1.130)$ \\
\hline Public/Private Dummy & $1.99 * *(7.32)$ \\
\hline Note: pseudo $R^{2}=.16, N=122,{ }^{*} p \leq .05,{ }^{* *} p \leq .01$ &
\end{tabular}

Hix index as opposed to other commonly used rankings such as the peer evaluation-based lists developed by the U.S. National Research Council and the U.S. News and World Report (2007), because of the many cited problems with such rankings and their basis in other characteristics beyond research productivity. ${ }^{2}$ Additionally, we used the Hix index rather than other rankings that are based on content analysis of leading political science journals (Welch and Hibbing 1983), because most of these measures only look at a very small number of political science journals. Miller, Tien, and Peebler (1996) only examined the content of the American Political Science Review (APSR; see also Garand and Graddy 1999); McCormick and Rice (2001) counted articles in APSR, the American Journal of Political Science (AJPS), the Journal of Politics (JOP), the Western Political Quarterly (WPQ), and Polity; and Ballard and Mitchell (1998) looked at APSR, JOP, AJPS, World Politics, Comparative Politics, the British Journal of Political Science (BJPolS), WPQ, Polity, and Political Science Quarterly. Furthermore, most indices only include the top 20 to 50 institutions, relegating the others to a common lower ranking. Only the Hix index examined all political science programs (including PUIs) and used 63 international political science journals to measure research productivity. It is the most complete ranking of research productivity currently in existence.

The second independent variable measured the size of the program, for which we listed the total number of FTE faculty reported by the department. ${ }^{3}$ In addition, we also identified the total population of students as an indicator and recoded this variable into four categories: 1 to 5,999 (1); 6,000 to 12,999 (2); 13,000 to 19,999 (3); and 20,000 and above (4). Finally, as an additional control variable, we coded whether the department was considered a public institution (state supported in some way) 4 or an exclusively private institution, with a 1 assigned to a state-supported institution and a o to private institutions.

\section{WHERE ARE GRADUATE TEACHING COURSES OFFERED?}

Table 1 shows the regression (using binary logit analysis) of the dependent variable-whether or not the department offers a course on teaching political science-against the set of independent variables. As indicated, of the four independent variables, two demonstrate a statistically significant relationship with whether or not the department offers a course on teaching political sciencethe inverse ranking on the Hix index and the public/private institution dummy variable. In other words, the more highly ranked 
the department in terms of research productivity, the less likely that the department offers a course on teaching political science. This result might suggest a specialization of departments, with less research-productive departments more likely to embrace a teacher-training mission for their graduate program. However, one should not overinterpret this finding-the strength of the relationship is actually quite weak, and many research intensive departments (such as the University of Indiana; the University of California, Berkeley; and Ohio State University) offer such courses. Indeed, a change of one position in the Hix rankings decreases the likelihood of an institution offering a graduate-level teaching course by about seven-tenths of $1 \%, \exp (b)=1.007$. Nonetheless, generally speaking, there does appear to be some degree of tradeoff in research productivity rankings and commitment to teacher training (see table 1 ).

In addition, departments housed in public institutions are significantly more likely to offer a graduate-level course on teaching political science than are private institutions. In fact, public institutions are approximately seven times more likely $(\exp [\mathrm{b}]=7.32)$ than private institutions to offer a graduate-level course on teaching. This finding of a greater likelihood that public institutions offer at least one course for graduate students on teaching political science may be due in part to the public service component of state institutions or the fact that public institution are consistently faced with state-mandated programs to enhance teaching generally (e.g., assessment). It may also be the case that a large proportion of private institutions rank highly in research productivity as opposed to public institutions, although this potential correlation does not produce collinearity problems in the model. (We ran variance inflation factor scores, and all values were less than 2 , indicating that there was not a problem associated with multicollinearity.)

The other two independent variables measuring the size of the department and the institution (which also measure, in some sense, the resource capacity of the department) were not related to whether the department offered a course on teaching. Thus, the offering of a course on teaching is not dependent on resources and a stretched faculty, but rather appears to be a matter of whether the department chooses to train political science teachers.

A second question we addressed is the extent to which departments require graduate students to take a course on teaching. Again, we operationalized this question in terms of whether anyone was required to take the course (coded as 1) or whether the course was offered primarily as an occasional elective. As mentioned previously, 41 departments offered such a graduate course. Table 2 shows the results of a regression of the dependent variable (whether the course was required).

As indicated, none of the independent variables are related to whether or not the department requires their graduate students to enroll in a teaching political science course. Thus, it appears that although institutional and departmental characteristics may affect whether such a course is offered, whether the course is required is a matter of choice, not affected by constraints.

\section{WHAT KINDS OF TOPICS ARE COVERED \\ IN GRADUATE TEACHING COURSES?}

What kinds of topics are covered in these courses? Of the departments that offer a graduate-level course on teaching political science, we were able to procure 13 sample syllabi from both programs that required the course and programs in which the

Table 2

Graduate Course on Teaching Political Science Required Among Departments Offering a Course: Coefficient Estimates, Logit Analysis

VARIABLE

\begin{tabular}{lc}
\hline Inverse of the Hix Index & $.001(1.001)$ \\
\hline FTE Faculty in Department & $.013(1.013)$ \\
\hline Total University Student Population & $-.216(1.241)$ \\
\hline Public/Private Dummy & $-.138(1.148)$ \\
\hline
\end{tabular}

Note: pseudo $R^{2}=.01, N=41,{ }^{*} p \leq .05,{ }^{* *} p \leq .01$

courses were offered as optional electives. Three coders were used to content analyze the 13 syllabi. The syllabi themselves were from a variety of different institutions, ranging from large, highly ranked research-intensive institutions (both public and private) to smaller programs at regional universities.

Each coder was asked to examine the basic design of the course, including the list of requirements and assignments, the total number of assigned readings for the course, and whether the course planned to use guest lecturers. Additionally, we examined the topical content of the courses, such as the percentage of the class sessions that were devoted to syllabus construction, the percentage of sessions devoted to teaching techniques, the types of teaching techniques discussed, and whether or not there was some attention paid to the development of a philosophy statement or teaching portfolio. The results were then compiled, and if there were any discrepancies, they were resolved by the faculty member directing the project. The results are presented in table 3 .

Given that we have only a very small sample of syllabi to analyze, inferences should be drawn with some care. Nonetheless, some interesting results emerge from the data reported in table 3. First, in terms of graded assignments, a wide variety of different (and innovative) assignments were used to assess the performance of the students in the course, ranging from studentdesigned syllabi $(n=7)$, lesson plans $(n=2)$, and sample assignments (e.g., exams or paper assignments, $n=5$ ) to sample teaching statements, grading and assessment exercises, videotapes of sample lectures, and the design of a teaching Web site.

Most courses had fewer readings than would appear in a typical graduate seminar (although one assigned 31 readings), with a median value of 14 entries (two courses, both at highly ranked research institutions, assigned no readings at all). Most of the courses spent some time on syllabus construction and course design (although, again, one course spent no time on this issue). Most courses focused the bulk of their time on teaching techniques and assignment construction.

A variety of different teaching themes were covered in the 13 syllabi. Some topics were expected, such as lecture preparation and lecture techniques $(n=6)$, assignment construction, and methods to promote classroom discussion. However, many courses focused on grading techniques, classroom management issues (such as dealing with unruly students), and teaching diversity. Other topics included interacting with students outside of class, the ethics of teaching, dealing with cheating and issues of academic honesty, designing Web sites, and "non-classroom 
Table 3

\section{Content Analysis of Course Syllabi $(N=13)$}

TYPE OF GRADED ASSIGNMENTS

\begin{tabular}{|c|c|c|c|c|}
\hline TYPE OF GRADED ASSIGNMENTS & $\begin{array}{l}\text { TIMES THEME } \\
\text { MENTIONED }\end{array}$ & $\begin{array}{l}\text { MEAN } \\
(S D)\end{array}$ & MEDIAN & RANGE \\
\hline Syllabus & 7 & & & \\
\hline Sample Assignments (Exams, Papers) & 5 & & & \\
\hline Presentation/Mini Lecture (in Class) & 4 & & & \\
\hline Faculty Observation of Teaching Course (Out of Class) & 4 & & & \\
\hline Shadow Class Reports & 4 & & & \\
\hline Peer Assessment & 3 & & & \\
\hline Teaching Statement/Philosophy & 3 & & & \\
\hline Class Lesson Plan & 2 & & & \\
\hline Grading Exercise & 2 & & & \\
\hline Assessment Exercise & 1 & & & \\
\hline Videotape of Own Lecture & 1 & & & \\
\hline Teaching Web Site & 1 & & & \\
\hline Reflective Paper & 1 & & & \\
\hline
\end{tabular}

\section{TYPES OF TEACHING TECHNIQUES MENTIONED}

\begin{tabular}{|c|c|c|c|c|}
\hline Lecture Preparation/Lecture Techniques & 6 & & & \\
\hline Constructing Assignments & 6 & & & \\
\hline Leading Discussions & 5 & & & \\
\hline Grading & 5 & & & \\
\hline Classroom Management Techniques & 5 & & & \\
\hline Learning Theories & 4 & & & \\
\hline Teaching Diversity & 3 & & & \\
\hline Using Technology & 3 & & & \\
\hline Assessment & 2 & & & \\
\hline Interacting with Students (Outside of Class) & 2 & & & \\
\hline Understanding Student Motivation & 2 & & & \\
\hline Ethics of Teaching & 1 & & & \\
\hline Cheating and Academic Honesty & 2 & & & \\
\hline Teaching Quantitative Methods & 1 & & & \\
\hline Designing Web Sites & 1 & & & \\
\hline Distance Learning & 1 & & & \\
\hline Non-Classroom Learning & 1 & & & \\
\hline Total Number of Assigned Readings & & $13.15(9.85)$ & 14 & $0-31$ \\
\hline Percent of Class Sessions Devoted to Syllabus Construction & & $8 \%(5 \%)$ & $8 \%$ & $0 \%-15 \%$ \\
\hline Percent of Sessions Devoted to Teaching Techniques (including Assignment Construction) & & $68 \%(17 \%)$ & $70 \%$ & $40 \%-93 \%$ \\
\hline Number of Sessions Using Guest Lectures & 6 & & & \\
\hline Number of Sessions Devoted to Teaching Portfolio & 5 & & & \\
\hline Number of Sessions Devoted to Teaching Philosophy & 4 & & & \\
\hline
\end{tabular}

learning" (or cocurricular learning) and its integration into the class. Finally, most of the courses covered issues related to fashioning a teaching philosophy (9 of the 13 courses had sessions devoted to that topic).

In sum, then, although we are not in a position to analyze the relationship between the themes covered in the courses offered and the structural characteristics of the departments and universities (which is part of the next phase of this project), it is apparent from the content analysis of the sample of syllabi that a wide variety of themes, techniques, and assignments is covered in these graduate-level courses dedicated to preparing graduate students for their future teaching role. 


\section{INTEGRATING TEACHER TRAINING INTO} THE GRADUATE PROGRAM: TWO CASES

A number of innovative programs have sought to better prepare their Ph.D. graduates for careers as college-level political science teachers by integrating teacher training into the graduate program. Two bear mentioning here: a new Ph.D. program in political science developed at Baylor University in Waco, Texas, and the College Professor Training Program at Miami University in Oxford, Ohio. The Baylor University program illustrates the design of a PhD. program that, from the very beginning, has treated the teacher training function as the cornerstone of the degree program. The Miami University program represents an older program that was added into the graduate curriculum as a structured, voluntary program.

\section{Baylor University}

The Ph.D program in political science at Baylor University in Waco, Texas, is of very recent origin. In response to a university-wide effort to upgrade the research and scholarly profile of the institution (known as the 2012 Vision), the department of political science sought to establish a new Ph.D. degree program in political science. Dr. Mary Nichols, previously of Fordham University, arrived at Baylor with a mandate to build the new program from the ground up. From the beginning, the Baylor University program sought to focus on particular strengths (as recommended by teaching, noting that although "too often ... teacher training is little more than an afterthought in graduate education," recent efforts such as the Teaching and Learning Conference, the publication of the Journal of Political Science Education, and the activities of the Political Science Education Section of APSA have renewed the focus on teaching. APSA has recognized this problem and sought to rectify it. Baylor's program sees itself as part of that new trend.

Thus, an integral part of the Baylor program is to put into place, as part of the degree, a systematic way to prepare future teaching faculty in political science. However, there were two major considerations when constructing the teacher preparation program. The first was the conviction that teacher training should focus less on the transmission of techniques and more on the transmission of experience, particularly the development of a mentoring relationship between teaching faculty and graduate students. Under this plan, graduate students would act in the role of apprentices. The second consideration was the resource constraints that face many mid-sized and smaller departments. Offering a course dedicated to teaching, as many other departments do, would consume resources and time, which is especially important for graduate students, who want to finish their coursework and degrees in a timely fashion.

The Baylor solution is quite unique. Rather than including a course or a series of courses designed to instruct students in how

\section{Rather than including a course or a series of courses designed to instruct students in how to teach, graduate students are apprenticed to senior faculty in the department.... In their second and third years in the program, the students are asked to work with a faculty member on a course as teaching apprentices. They are not assigned as assistants to an undergraduate course, but rather participate in the course itself, doing all of the readings and completing a project (e.g., designing a different annotated syllabus for the course) to earn three directed reading credits (these credits are a normal part of the graduate student requirements and do not add time to the students' tenure in the program).}

the APSA Task Force on Graduate Education for smaller Ph.D. programs) by specializing in "constitutional government, statecraft, and citizenship," "religion and politics" and teaching preparation-the Baylor Web site notes, "It is our intention to do 'a few things,' and to do them very well. Our program, moreover, is intended to address gaps in graduate education in this country" (Baylor University n.d.). The first students entered the program in the 2004-05 school year. Currently, 19 graduate students are enrolled in the Ph.D. program, and all are fully funded. 5

Traditional strengths of the university have been the study of Western political philosophy and constitutional politics. Further, the department has sought to situate the program within the context of the "Christian mission" of the university, focusing on political philosophy as well as constitutional politics and religion and politics. Finally, the program emphasizes another key element of Baylor's identity, namely, the centrality of teaching to the mission of the university, which contends that "teaching is one of the greatest examples of a Christian vocation or calling" (Baylor University n.d.). Furthermore, the program emphasizes new trends in the political science discipline in the hope of promoting better to teach, graduate students are apprenticed to senior faculty in the department. First-year students take the general required seminars and introductory-level courses. However, in their second and third years in the program, the students are asked to work with a faculty member on a course as teaching apprentices. They are not assigned as assistants to an undergraduate course, but rather participate in the course itself, doing all of the readings and completing a project (e.g., designing a different annotated syllabus for the course) to earn three directed reading credits (these credits are a normal part of the graduate student requirements and do not add time to the students' tenure in the program). Graduate students are free to choose the course in which they want to apprentice, whether a lower division lecture course or an even or upper division seminar, subject to the approval of an instructor, who draws up a contract that is then approved by the graduate director. Thus, apprentice assignments are not based on the needs of the faculty, such as the necessity of grading large sections of American government, but on the interests of the graduate students.

In the fourth year of the program, graduate students are assigned their own courses to teach (generally lower division 
introductory level courses) and are considered "teachers of record." As such, they are responsible for the conduct and grading of the course, although textbooks and the basic structure of the class are generally predetermined. In the fifth year of the program, students are expected to focus entirely on writing their dissertations.

\section{Miami University}

The College Professor Training Program, housed in the department of political science at Miami University, was developed in 2001 and 2002 by the director of graduate studies, John Rothgeb, and the chair of the department, Ryan Barrilleaux. Unlike the Baylor University program, which was motivated by trends in the APSA and the university's desire to upgrade the research character of the institution, the Miami University program was launched as a natural extension of the mission of the department, which has historically prided itself on producing college teachers. Also unlike the Baylor program, which took a cue from the 2004 APSA report on graduate education, the Miami University program predated APSA's study. Nonetheless, the development of the Miami University program, like the Baylor University program, was motivated by the recognition of the need to produce faculty who could teach at smaller, primarily undergraduate institutions. Miami University had a comparative advantage in this regard. The university's Ph.D program in political science, which has been in existence since the 1970 , has long maintained a tradition of training political science teachers. However, it was only in 2002 that a more formal program was developed to "familiarize its Ph.D. students with all aspects in the life of a university" (interview with John Rothgeb, July 2009). Partly influenced by the philosophy of the PFF program, the political science program nonetheless has fashioned its approach in a unique way. The goal is to produce students who "significantly enhance their appeal to colleges and universities and increase the probability of obtaining jobs and getting promotions once they are employed" (interview with John Rothgeb, July 2009). Recruitment into the graduate program targets students who seek a career as a political science teacher, particularly undergraduate students at liberal arts colleges and universities.

On the surface, the Miami University program resembles other graduate programs. Graduate students act as teaching assistants, with grading and other responsibilities. Only after the completion of their comprehensive exams do they teach courses independently. However, the Miami University program uniquely requires students slotted to teach independent courses to participate in the College Professor Training Program. The program includes activities in seven areas of university life: teacher training, recruitment and retention, student life, diversity training, administration, supplementary instruction aids, and program design. Unlike the Baylor program, all activities are voluntary-although the vast majority of Ph.D. graduate students participate, and students slotted to teach courses are required to participate. Facing resource constraints, the Miami University program takes advantage of existing campuswide resources that are offered to faculty members on a regular basis by the university's teaching and learning center. All graduate students are strongly encouraged to participate in workshops related to a variety of different issues regarding teaching, including:

\section{Teacher Training}

- Coursework in teaching political science to undergraduates

- Mentor program to train students for independent teaching
- Independent undergraduate teaching opportunities

- Graduate student colloquia presentations

- Participation in the Lilly conference on college teaching

- Community for the Enhancement of Learning and Teaching (CELT) seminars

2. Supplementary Instructional Aids

- Workshop on teaching writing to undergraduates

- Workshop on study abroad opportunities and internships

- Workshop on the Model U.N. and other simulations

- Workshop on legal issues in higher education

- Workshop on the Internet and instruction

- Workshop on the use of movies in teaching

\section{Program Design}

- Participate in graduate program review committee

- Assist with surveys of college and university programs

- Assist in establishing course syllabus banks

4. Diversity Training

- Participate in diversity workshop planning

- Participate in diversity workshops

- Assist in recruiting minority students

In addition, the department offers internal workshops on particular issues. All of these activities are coordinated by the graduate director.

Thus, the examples of the Baylor University and the Miami University Ph.D. programs illustrate ways in which to integrate teacher training into the graduate curriculum without too great a strain on resources or faculty time.

\section{CONCLUSION}

In this article, we seek to investigate three questions: Why would a department offer a course on teaching political science at the graduate level? What topics are generally covered in such courses? Are there examples of political science Ph.D. programs that have sought to fully integrate training of college teachers into the curriculum, and what are their features?

Generally, the quantitative analysis supports the general perception that the more highly ranked, research-productive departments generally do not offer courses dedicated to college teaching, despite some important exceptions such as the University of California-Berkeley, the Ohio State University, and the University of Wisconsin. Nonetheless, the relationship is rather weak, which may be due to another striking finding: public institutions are seven times more likely to offer a course dedicated to teaching than are private institutions. This statistic may indicate that even for highly ranked, public, research-productive departments, an institutional culture of public service remains, which would include teacher training. This culture would, in part, explain why the relationship between the Hix index and whether or not a course dedicated to teaching is offered is generally weak-a number of highly ranked public institutions do offer such courses, whereas most highly ranked departments at private institutions generally do not.

In terms of the kinds of topics covered, a wide variety of topics and assignments appear on the small sample of syllabi we content analyzed. This variation is quite encouraging, in that there are many innovative techniques and topics covered in these 
courses, and not simply the basics of teaching. In a future iteration of this research, we would like to expand the number of syllabi we content analyze and relate their characteristics with departmental and institutional characteristics. For instance, we might pose the question: are different topics covered in syllabi offered at highly ranked Research I schools (who see their graduates teaching at other highly ranked departments) and syllabi at lower ranked departments?

Finally, there are clearly ways in which college teacher training can be fully incorporated into the graduate curriculum. Both Baylor and Miami University's programs offer alternative costeffective ways to achieve such integration, although using very different models-one based on the apprentice system, the other using more traditional resources to supplement their program, such as the faculty development or teaching and learning centers found at most universities. Both use innovative techniques to provide better teacher training opportunities for their graduate students.

As Ph.D.-granting departments seek to establish their niches as recommended by the APSA Report on Graduate Education, and as they seek to adjust to the changing labor market facing their graduates, having a comparative perspective on what is currently being done in the field across the country is increasingly important. Knowing the innovations being employed elsewhere can help many departments find their place in the sun.

\section{NOTES}

1. The lower figure is presented by Nerad and Cerny (2003), who report positions at Carnegie classification research I institutions; Lopez (2003) reports a figure of $35 \%$ in doctoral granting departments, which may include departments in schools that are not classified as research I institutions.

2. There have, of course, been several noteworthy problems with the peer evaluation-based approach. In particular, such assessments are largely subjective. The biases of this approach have been investigated, and it has been argued that because the sample of academic judges only has very limited information about the output of departments, they are forced to base their judgments on reputation, which favors already established programs at the expense of developing programs (Katz and Eagles 1996). Furthermore, the reputation of the department may be confounded by the reputation of the institution as a whole, which some researchers have referred to as the "halo effect" (Lowry and Silver 1996; Jackman and Siverson 1996). Second, the peer assessments are quite costly to conduct and hence are updated infrequently.

3. If this number was not explicitly reported, we counted the number of full, associate, and assistant professors in a department, excluding any faculty listed as visiting, or adjunct, or temporary professors or lecturers from the count.

4. The state-supported category included institutions such as the University of Pittsburgh and Miami University (Ohio), which although independently funded like a private institution in many ways, is supported in part by state funding.

5. The information from this section is largely from an interview with Dr. Mary Nichols, chair of the department of political science, Baylor University, January 19, 2009.

\section{REF ERENCES}

APSA Task Force on Graduate Education. 2004. "Report to the Council." PS: Political Science and Politics 38: 129-35.

Ballard, M. J., and N. J. Mitchell. 1998. "The Good, the Better, and the Best in Political Science." PS: Political Science and Politics 31 (4): 826-28.

Baylor University. n.d. "Doctor of Philosophy in Political Science." http:// www.baylor.edu/political_science/index.php?id=69540.

Buehler, Melissa, and Anthony Marcum. 2007. "Looking into the Teaching Crystal: Graduate Teaching and the Future of Political Science." Journal of Political Science Education 3 (1): 21-38.

Cole, Alexandra, and John Ishiyama. 2008. "Who Produces the Great Teachers? Ranking Graduate Political Science Programs via Teaching Awards.” Paper presented at the annual meeting of the APSA Teaching and Learning Conference, San Jose, CA, February 22-24.

Gaff, Jerry G., Anne S. Pruitt-Logan, Leslie B. Sims, and Daniel D. Denecke. 2003. Preparing Future Faculty in the Social Sciences and Humanities. Washington, DC: Council of Graduate Schools and Association of American Colleges and Universities.

Garand, J. C., and K. L. Graddy. 1999. "Ranking Political Science Departments: Do Publications Matter?” PS: Political Science and Politics 32 (1): 113-16.

Hesli, Vicki L, Evelyn C. Fink, and Diane M. Duffy. 2003. "Mentoring in a Positive Graduate Student Experience: Survey Results from the Midwest Region.” PS: Political Science and Politics 36 (3): 457-60.

Hix, Simon. 2004. "A Global Ranking of Political Science Departments.” Political Studies Review 2 (2): 293-13.

Hoffer, Thomas B, Scott Sederstrom, Lance Selfa, Vince Welch, Mary Hess, Shana Brown, Sergio Reyes, Kristy Webber, and Isabel Guzman-Barron. 2002. Doctorate Recipients from United States Universities: Summary Report 2001. Chicago: National Opinion Research Center.

Jackman, R. W., and R. M. Siverson. 1996. "Rating the Rating: An Analysis of the National Research Council's Appraisal of Political Science Ph.D. Programs." PS: Political Science and Politics 29 (2): 155-60.

Katz, R., and M. Eagles. 1996. "Ranking Political Science Departments: A View from the Lower Half." PS: Political Science and Politics 29 (2): 149-54.

Lopez, Linda. 2003. "Placement Report: Political Science Ph.D.s and ABDs on the Job Market in 2001-2002." PS: Political Science and Politics 36: 835-41.

Lowry, R. C., and B. D. Silver. 1996. "A Rising Tide Lifts All Boats: Political Science Department Reputation and Reputation of the University." PS: Political Science and Politics 29 (2): 161-67.

Masuoka, N., B. Grofman, and S. Feld. 2007. "Ranking Departments: A Comparison of Alternative Approaches.” PS: Political Science and Politics 40 (3): 531-37.

McCormick, J. M., and T. W. Rice. 2001. "Graduate Training and Research Productivity in the 1990s: A Look at Who Publishes." PS: Political Science and Politics 34 (3): $675-80$

Miller, A. H., C. Tien, and A. A. Peebler. 1996. "Department Rankings: An Alternative Approach.” PS: Political Science and Politics 29 (4): 704-17.

Nerad, Maresi, and Joseph Cerny. 2003. Career Outcomes of Political Science Ph.D. Recipients: Results from the Ph.D.s Ten Years Later Study. Seattle, WA: Center for Research and Innovation in Graduate Education.

U.S. News and World Report. 2007. America's Best Graduate Schools 2007. Online ed. http://www.usnews.com/usnews/edu/grad/rankings/phdhum/brief/ polrank_brief.php.

Welch, S., and J. R. Hibbing. 1983. "What Do the New Ratings of Political Science Departments Measure?" PS: Political Science and Politics 16 (3): 532-40. 